\title{
Regeneração Natural de Anadenanthera colubrina (Vell.) Brenan Fabaceae em Brejo de Altitude em Bananeiras, Paraíba
}

\section{Natural regeneration of Anadenanthera colubrina (Vell.) Brenan Fabaceae in Altitude Swamp in the county of Bananeiras, Paraíba, Brazil}

\author{
Ivan Sérgio da Silva Oliveira ${ }^{1}$, Vênia Camelo de Souza ${ }^{2}$, Robson Luis Silva de Medeiros ${ }^{3 *}$, Miguel Avelino Barbosa Neto ${ }^{4}$, Alex \\ da Silva Barbosa ${ }^{5}$, Gilvaneide Alves de Azeredo ${ }^{5}$
}

\begin{abstract}
Resumo: A destruição de habitats atrelada à fragmentação causa sérias consequências para qualquer tipo de vegetação, principalmente para a Floresta Atlântica na Região Nordeste. O estudo teve como objetivo avaliar a dinâmica populacional da regeneração natural da espécie, Anadenanthera colubrina, Fabaceae, ocorrente em fragmento florestal do Centro de Ciências Humanas, Sociais e Agrárias da Universidade Federal da Paraíba. Foi selecionada uma população, e foram plotadas aleatoriamente 10 parcelas $(10 \times 10 \mathrm{~m})$, totalizando uma área amostral de $1.000 \mathrm{~m}^{2}$, onde todos os exemplares menor ou igual a $0,30 \mathrm{~cm}$ de altura foram marcados. O estudo foi realizado entre os meses de dezembro de 2014 e julho de 2015 . Foram avaliados, altura, diâmetro do colo, número de folhas, número de indivíduos e taxa de mortalidade. As variáveis se ajustaram ao modelo de regressão quadrática, e cúbica. Com relação a taxa de mortalidade, foi de 85,45\%. Algumas parcelas, apresenta localização, ou por menor ação antrópica ou competitiva, apresentaram aumento no número total de indivíduos. O crescimento de plântulas de A. colubrina foi maior onde as parcelas estão localizadas ao centro do fragmento estudado, ou seja, em área com menor influência antrópica, ou próximo a fontes hídricas.
\end{abstract}

Palavras chave: Angico; Indivíduos regenerantes; Mortalidade; Fragmentação.

\begin{abstract}
The Atlantic Forest is currently the most threatened biome due to various anthropogenic pressures. The destruction of habitats linked to fragmentation causes serious consequences for any type of vegetation, especially in the Atlantic Forest in the Northeast of Brazil. The angico, Anadenanthera colubrina, Fabaceae, is an arboreal species with a height of 12-15 m. The study aimed to understand the natural regeneration and evaluate the recruitment of seedlings, occurring in a forest fragment of the Centro de Ciências Humanas, Sociais e Agrárias da Universidade Federal da Paraíba. We selected a population of A. colubrina and 10 random plots $(10 \times 10 \mathrm{~m})$ were plotted, with a total sample area of $1,000 \mathrm{~m}^{2}$, where all copies of angico less than or equal to $0.30 \mathrm{~cm}$ were marked. The study was conducted between the months of December 2014 and July 2015 , It was evaluated, height, stem diameter, number of leaves, number of individuals and mortality. The variables set to the linear, quadratic, and cubic regression model. Regarding the mortality rate was $85.45 \%$. Some plots because of its location, or, less human action or competitive, showed an increase in the total number of individuals. The perpetuation of this species in the studied fragment depends mainly on appropriate conditions for seed germination as soon as dispersed and the presence of young plants that occur in the forest understory.
\end{abstract}

Keywords: Angico; Regenerating individuals; Mortality; Fragmentation.

\footnotetext{
*Autor para correspondência

Recebido para publicação em 19/07/2017; aprovado em 15/09/2017

${ }^{1}$ Bacharel em Agroecologia, Mestrando em Ciências Agrárias (Agroecologia), Centro de Ciências Humanas Sociais e Agrárias da Universidade Federal da Paraíba. Campus Universitário III, S/N. Cidade Universitária, 58220-000, Bananeiras, Paraíba. E-mail: ivantecagro@gmail.com

${ }^{2}$ Bióloga, Doutora em Agronomia, Departamento de Ciências Básicas e Sociais, Centro de Ciências Humanas Sociais e Agrárias da Universidade Federal da Paraíba. E-mail: venia_camelo@hotmail.com

${ }^{3}$ Licenciado em Ciências Agrárias, Mestrando em Agronomia (Produção Vegetal), Faculdade de Ciências Agrárias e Veterinárias da Universidade Estadual Paulista, Jaboticabal, São Paulo. E-mail: robsonluissm@gmail.com

${ }^{4}$ Licenciado em Ciências Agrárias, Mestrando em Agronomia, Centro de Ciências Agrárias da Universidade Federal da Paraíba, Areia, Paraíba. E-mail: miguelavelinoneto18@gmail.com

${ }^{5}$ Licenciado em Ciências Agrárias, Doutor em Agronomia, Departamento de Agricultura, Centro de Ciências Humanas Sociais e Agrárias da Universidade Federal da Paraíba, Bananeiras, Paraíba. E-mail: aldasibarbosa@gmail.com

${ }^{6}$ Eng Agrônoma, Doutora em Agronomia, Departamento de Agricultura, Centro de Ciências Humanas Sociais e Agrárias da Universidade Federal da Paraíba, Bananeiras, Paraíba. Email: azeredogil@yahoo.com.br
} 


\section{INTRODUÇÃO}

O estudo de fenômenos conexos a variações na estrutura das comunidades vegetais tem cada vez mais envolvido a avaliação do potencial regenerante da estrutura arbórea, essa regeneração natural torna as florestas capazes de se restaurarem após distúrbios naturais ou antrópicos (MARCHESINI et al., 2009). Os efeitos procedentes das ações antrópicas causam alterações na dinâmica das florestas nativas, influenciando a estrutura e a regeneração das populações de espécies florestais (AVILA et al., 2016).

A destruição de habitats atrelada à fragmentação causa sérias consequências para qualquer tipo de vegetação, principalmente para a Floresta Atlântica na Região Nordeste que se encontra extremamente fragmentada e no contexto local, especificamente os Brejos de altitude e ecossistemas associados no Estado da Paraíba (MEDEIROS et al., 2016). Por apresentar condições climáticas bastante favoráveis à agricultura, os brejos de altitude têm sido considerados áreas prioritárias de ocupação e desenvolvimento de atividades de pecuaristas e agricultores (MEDEIROS et al., 2017).

Desta forma espécies que ocorrem nesses fragmentos, provavelmente, estão tendo algum tipo de impacto necessitando de estudos que relacionem dados de estrutura populacional. O conhecimento da biodiversidade de uma região constitui um pré-requisito básico para o manejo e a gestão do seu patrimônio genético. Principalmente, no que se refere às espécies vegetais, é fundamental conhecer as preferências das mesmas por determinados sítios ou condições biofísicas que possam determinar a abundância de suas populações ou mesmo a distribuição geográfica desses táxons (ANDRADE et al., 2008).

Os Brejos de Altitudes nordestinos são áreas que apresentam microclimas dissociantes do contexto onde estão inseridos (semiárido). Essa umidade característica está associada ao efeito orográfico, planaltos e chapadas entre 600 e $1.100 \mathrm{~m}$ de altitude, que aumentam os níveis de pluviosidade e diminuem as temperaturas, o que forma "ilhas" de microclima diferenciado. Suas formações florestais são disjunções de floresta atlântica, ilhadas pela vegetação da Caatinga, condição que torna essas remanescentes áreas de elevada biodiversidade (BARBOSA et al., 2004). Possivelmente, espécies que ocorrem nesses fragmentos estão tendo algum tipo de impacto, necessitando de estudos que relacionem dados de estrutura populacional e dinâmica, imprescindíveis para indicar espécies que necessitam de ações conservacionistas (MEDEIROS et al., 2016).

A capacidade de resiliência do ecossistema pode ser medida por meio de avaliações da vegetação (REIS et al., 2007). Diferenças no sucesso de estabelecimento pósdispersão ocorrem basicamente devido a mudanças nas taxas de germinação, competição, herbivoria e estresse hídrico e microclimático, que alteram a sobrevivência e o crescimento das plântulas (ALVES et al., 2006).

Anadenanthera colubrina (Vell.) Brenan Fabaceae, popularmente conhecida como angico, é uma espécie arbórea com altura entre $12-15 \mathrm{~m}$ e tronco de $30-50 \mathrm{~cm}$ de diâmetro. Sua madeira é útil para construção civil, obras hidráulicas, confecção de dormentes, tabuado, podendo ainda ser aproveitada para arborização de parques e praças e para plantio em florestas mistas destinadas à recomposição de áreas de preservação degradadas (LORENZI, 2002).

Acredita-se que sob floresta desenvolvida a conservação de recursos seja estratégia necessária para o desenvolvimento e sobrevivência da regeneração natural. Dessa forma, é esperado que o indivíduo da regeneração natural deva manter relação proporcional de crescimento em altura e diâmetro para sua sobrevivência (PALUDO et al., 2011).

$\mathrm{O}$ estudo teve como objetivo avaliar a dinâmica populacional da regeneração natural da espécie Anadenanthera colubrina, Fabaceae ocorrente em fragmento florestal do Centro de Ciências Humanas, Sociais e Agrárias da Universidade Federal da Paraíba (CCHSA/UFPB).

\section{MATERIAL E MÉTODOS}

\section{Local da pesquisa}

A pesquisa foi desenvolvida em um remanescente de Floresta Ombrófila Aberta, pertencente a Reserva Florestal da Universidade Federal da Paraíba (CCHSA/UFPB), Campus III. É considerado um importante fragmento florestal ecotonal de Brejo de Altitude. Está situada na microrregião de Brejo Paraibano, na Cidade de Bananeiras, Paraíba. Possuindo um de seus principais fragmentos aproximadamente 35,5 ha, cujas coordenadas são: $6^{\circ} 46^{\prime} \mathrm{S}$ e $35^{\circ} 38^{\prime} \mathrm{W}$. Gr. com altitude variante entre 510 e $617 \mathrm{~m}$ de altitude. O clima da região é o As' (tropical chuvoso) quente e úmido (Classificação de Köppen) e se caracteriza por apresentar temperatura máxima de $38^{\circ} \mathrm{C}$ e mínima de $18^{\circ} \mathrm{C}$, com chuvas de outono a inverno (concentradas nos meses de maio a agosto). O solo da reserva é do tipo Latossolo amarelo distrófico, textura franco arenosa a franco argilosa, fase floresta tropical subperenifólia. Geomorfologicamente caracteriza se pelo relevo suave ondulado (EMBRAPA, 1999).

O remanescente abriga importantes espécimes autóctones representantes da tipologia vegetal de grande importância fitogenética, ecológica e para o resguardo da fauna e flora local

\section{Amostragem da população}

No fragmento de floresta Ombrófila Aberta do CCHSA/UFPB foi selecionada uma população de Anadenanthera colubrina e aleatoriamente foram plotadas 10 parcelas $(10 \times 10 \mathrm{~m})$, totalizando uma área amostral de $1.000 \mathrm{~m}^{2}$ (Figura 1), onde todos os exemplares de angico menor ou igual a $0,3 \mathrm{~m}$ foram marcados. No levantamento foi utilizado o método das parcelas (MULLER-DOMBOIS; ELLEMBERG, 1974).

No interior das parcelas todos os indivíduos regenerantes de $A$. colubrina foram contados e marcados. $\mathrm{O}$ número designado para os indivíduos foi aleatório, tanto no início quanto no momento de seu aparecimento no censo. Mensalmente, entre os meses de dezembro de 2014 a julho de 2015 , as parcelas foram monitoradas para contagem de novos nascimentos e registro do número de mortes. Os parâmetros avaliados foram; quantidade de folhas, altura das plântulas e diâmetro caulinar na altura do solo. Realizou-se a contagem das folhas e para o registro de altura foi utilizado régua e para o diâmetro caulinar utilizamos um paquímetro digital inox LOTUSO. 
Figura 1. Localização geográfica das parcelas alocadas na reserva do Centro de Ciências Humanas, Sociais e Agrárias da Universidade Federal da Paraíba, remanescente de floresta Ombrófila Aberta no município de Bananeiras, Paraíba.

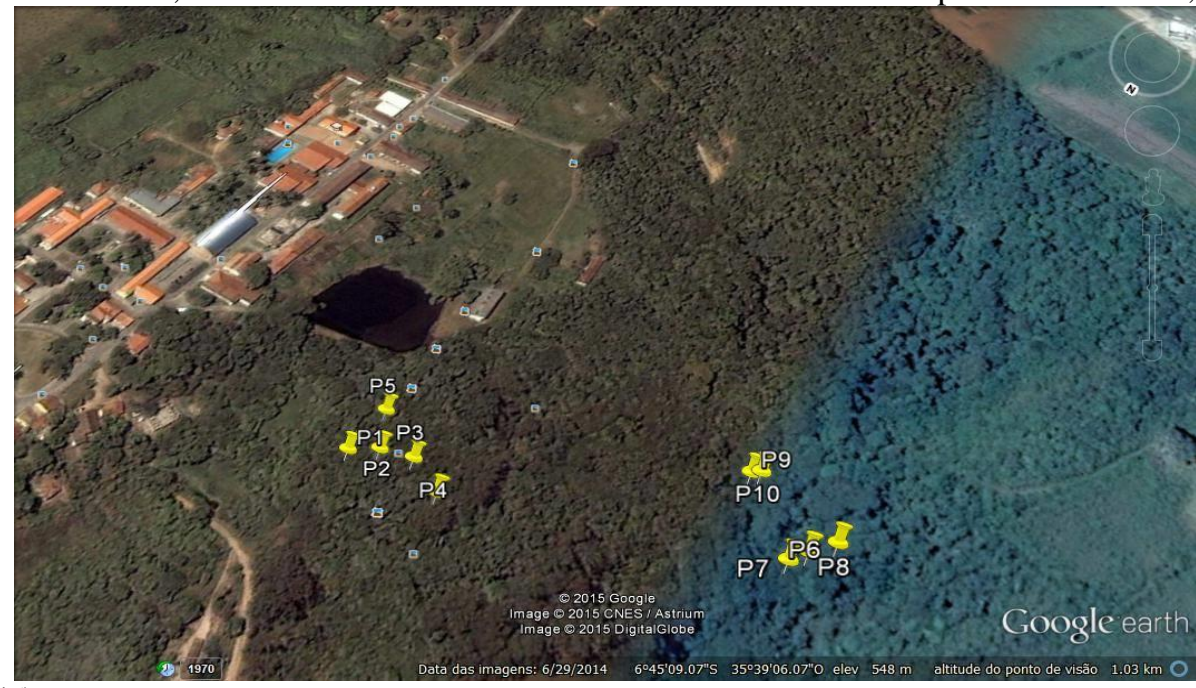

Fonte: Google Earth (2016)

\section{Análise dos dados}

Para as variáveis altura $(\mathrm{cm})$, diâmetro do colo $(\mathrm{mm})$ e quantidade de folhas dos indivíduos regenerantes de Angico, foi realizada, One-way, ANOVA utilizando software SAS 9.2, sendo significativo a regressão na qual os dados se ajustaram ao modelo quadrática e cúbica a $5 \%$. Para efeito de cálculo da taxa de mortalidade, utilizou - se por diferença, sendo, os indivíduos sobreviventes da primeira a última leitura, ou seja, os indivíduos marcados em dezembro e sobreviventes no mês de Julho. Os indivíduos ingressantes eram contabilizados para fazer a taxa de sobreviventes mensal. Com isso, os indivíduos ingressantes que não sobreviveram ao final do experimento foram contabilizados na taxa de mortalidade, foram obtidas as quantidades de indivíduos mortos e sobreviventes por parcela experimental.

\section{Dados pluviométricos}

Os dados referentes a pluviometria foram obtidos no sitio da AESA (Agência Executiva de Águas do Estado da Paraíba), os dados referentes a temperatura foram obtidos no sitio do Inmet (Instituto Nacional de Metereologia). Na Figura 2, estão apresentados os dados pluviométricos e a média da temperatura máxima e mínima mensais, durante a coleta de dados dos indivíduos regenerantes de angico. Verificamos que os meses com maior índice de pluviosidade foram março, junho e julho de 2015 , enquanto que os meses com menor pluviosidade foram dezembro de 2014 e janeiro e fevereiro de 2015.

Figura 2. Precipitação (mm) e Temperaturas do município de Bananeiras, Paraíba, nos anos de 2014 à 2015.

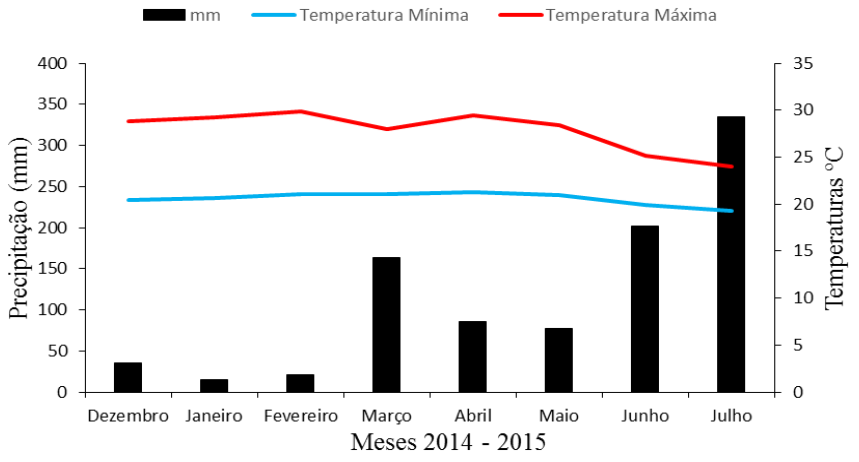

Fonte: AESA (2015)

\section{RESULTADOS E DISCUSSÃO}

No período do estudo foram registrados 105, 152, e 155 indivíduos nos meses de maio, junho e julho respectivamente, nesses meses a média foi inferior. Nos meses de abril e maio, foram registrados 124 e 133 indivíduos, não apresentaram os maiores registros quantitativos, porém, os meses com as menores médias de altura, são os meses que obteve-se a maior pluviometria do período de estudo, nesses meses, obteve-se alta quantidade de regenerantes ingressantes nas parcelas, porém estes, apresentaram menor tamanho, observou-se ainda, a ocorrência de mortalidade em relação as leituras anteriores, com isso, houve a presença de regenerantes em grande quantidade, porém, em tamanhos menores. Entretanto nos meses com maiores médias de altura, não registrou-se uma quantidade alta de novos indivíduos regenerantes e baixa mortalidade, havendo a manutenção de indivíduos que estavam presentes no Táxon.

As chuvas torrenciais registradas nos meses de março, junho e julho podem ter influenciado tanto na alta mortalidade, devido ao carreamento de plântulas ocasionado pela chuva, bem como, favorecido ao aparecimento de novos indivíduos regenerantes, haja vista a grande quantidade de matéria orgânica do solo que favorece o desenvolvimento de novas plântulas.

Os dados de altura dos indivíduos regenerantes de angico (Anadenanthera colubrina) se ajustaram ao modelo de regressão quadrática (Figura 3). A população cresce, com isso as médias da altura caulinar apresentaram no primeiro mês, média de $12,80 \mathrm{~cm}$ e no final as plântulas apresentaram média de altura igual a 13,94 $\mathrm{cm}$. O recrutamento em ambientes florestais pode ser influenciado por um conjunto complexo de interações ecológicas em diferentes escalas espaciais, incluindo efeitos de seca ou limitação de nutrientes (BURSLEM et al., 1996). Os dados obtidos referentes ao crescimento das plântulas, diâmetro caulinar e número de folhas indicam relação positiva, haja vista a relação entre mortalidade e recrutamento, ou seja, está ligado ao registro de mortos e recrutados durante o período experimental. Logo, é uma tarefa difícil que envolve dedicação, tendo em vista a complexidade e lentidão dos processos dinâmicos desses ecossistemas (SCHAAF et al., 2005). 
Figura 3. Altura de indivíduos regenerantes de angico (Anadenanthera colubrina) em população natural em área de mata, Bananeiras, Paraíba.

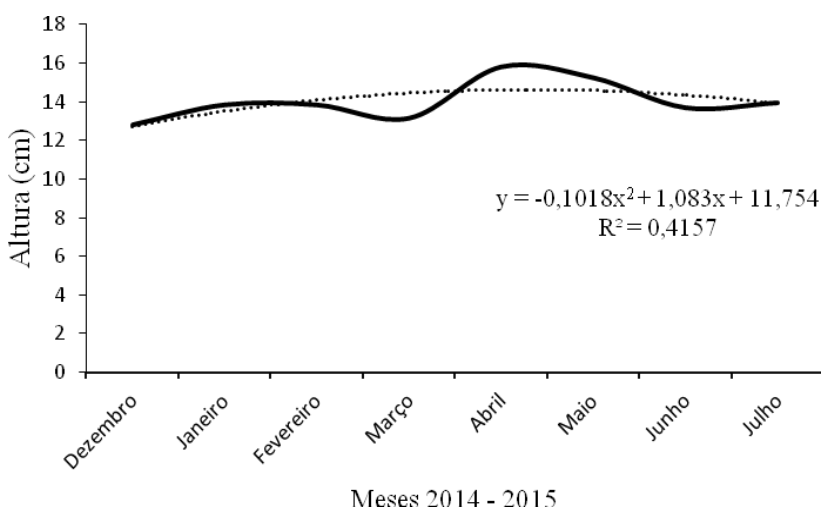

A população de Angico no fragmento florestal proporciona ampla dispersão na área, embora exista um número relativamente menor de indivíduos do estrato adulto, quando correlacionado com o estrato regenerante, sendo este fato bastante comum em formações florestais jovens (MEDEIROS et al., 2016). Os mesmos autores afirmam que o comportamento dispersivo (barocórica) colabora para garantir um grande contingente de sementes na serrapilheira, garantindo um fornecimento e apoio básico ao estoque de plântulas embaixo das copas dos indivíduos adultos e a ausência de distúrbios em larga escala, a dinâmica da regeneração é intensamente influenciada por fatores endógenos (estruturas da vegetação e interação entre espécies).

Os dados de diâmetro ao nível do solo (DNS) dos indivíduos regenerantes de angico (Anandenanthera colubrina) se ajustaram ao modelo de regressão quadrática (Figura 4). No mês 1 (Dezembro de 2014), foram marcadas 206 indivíduos da espécie.

Figura 4. Diâmetro de indivíduos regenerantes de angico (Anadenanthera colubrina) em população natural em área de mata, Bananeiras, Paraíba.

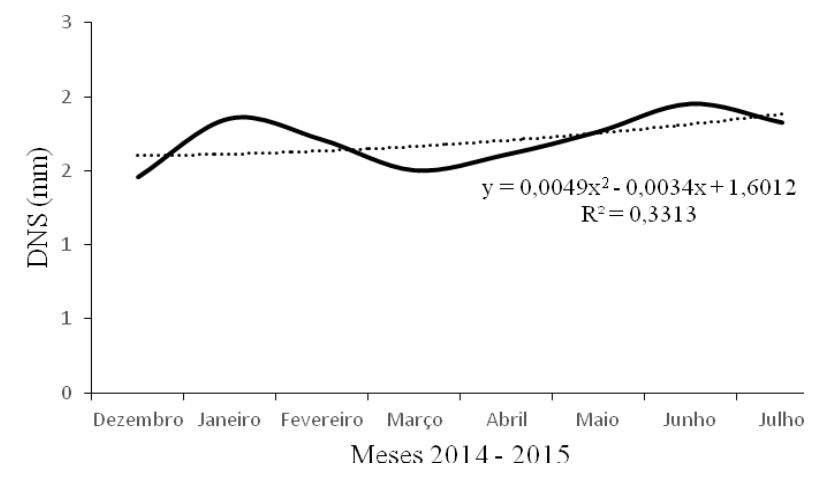

O diâmetro caulinar do táxon apresentou crescimento nos três meses iniciais, a primeira leitura apresentou uma média de $1,45 \mathrm{~mm}$ e final de $1,83 \mathrm{~mm}$, apresentando $0,38(\mathrm{~cm})$ de crescimento durante o período estudado, porém no mês de junho de 2015, devido aos indivíduos ingressantes que influenciaram no aumento da média mensal, no qual obtivemos um crescimento de $0,51 \mathrm{~cm}$. Já a mortalidade influenciou na perda do diâmetro nos meses de março e abril de 2015. Outro fator que atua fortemente na quantidade de indivíduos em fase de plântula é que as sementes deste táxon apresentam se vigorosas ao final do estádio de amadurecimento e não apresentam dormência tegumentar ou embrionária (LORENZI, 2002).

Os dados referentes ao número de folhas de angico (Anadenanthera colubrina) se ajustaram ao modelo de regressão quadrática (figura 5) com média de 18,94 no mês de dezembro de 2014, e no final (julho de 2015) a média foi de 24,22 . No mês de janeiro de 2015 , foi obtida a menor média do período estudado com 17,63, enquanto nos meses 5 e 6 foram obtidas médias 32,99 e 31,12 respectivamente. Este crescimento e o decréscimo é devido ao número de ingressantes nestes meses. Outro fator como chuvas podem ter influenciado.

Figura 5. Número de folhas de indivíduos regenerantes de angico (Anadenanthera colubrina) em população natural em área de mata, Bananeiras, Paraíba.

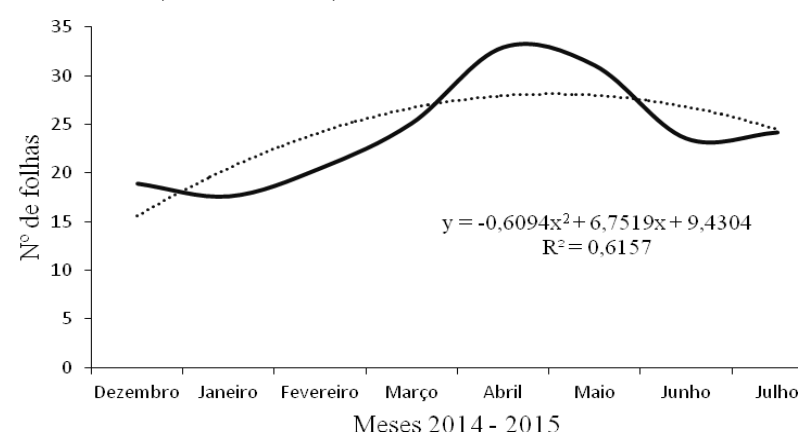

Marenco et al., (2014), concluíram em estudo sobre Fisiologia de espécies florestais da Amazônia, que na época seca observa-se aumento da irradiância o que pode eventualmente favorecer a fotossíntese. Entretanto, a limitação imposta pela restrição hídrica na época seca leva a redução da fotossíntese sobretudo em árvores de dossel. Árvores em fase juvenil estão menos expostas às variações na umidade do ar o que permite que as taxas de fotossíntese oscilem menos ao longo do ano quando o período de seca é de curta duração. Com isso, provavelmente o crescimento apresentado na quantidade de folhas das plântulas (Figura 5), provavelmente, está ligado a atividade fotossintética exercida pelo táxon e principalmente em se tratando da espécie estudada que é pioneira.

Os dados referentes a indivíduos sobreviventes de angico (Anadenanthera colubrina) foram obtidos das quantidades mensais de sobreviventes, incluindo os ingressantes, durante o período experimental, onde mesmo com a presença dos indivíduos ingressantes e sobreviventes, houve diminuição de $32,61 \%$ do total de indivíduos (Figura 6).

Figura 6. Indivíduos regenerantes de angico (Anadenanthera colubrina) sobreviventes mensais, em população natural em área de mata, Bananeiras, Paraíba.

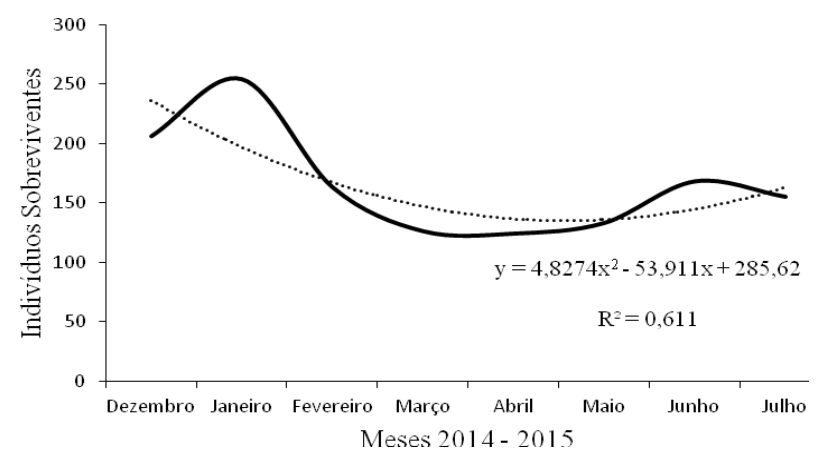


Na figura 7, observa-se os dados referentes a indivíduos sobreviventes de angico (Anadenanthera colubrina) obtidos das quantidades de sobreviventes por parcela ao final do período experimental, incluindo os ingressantes, constatandose que para os indivíduos ingressantes e sobreviventes houve diminuição de $100 \%$ nas parcelas 1,2 e 5, na parcela 6 a diminuição foi baixa com apenas $3,22 \%$, e crescimento nas parcelas 4 e 9 com $78,26 \%$ e $18,18 \%$ respectivamente do total de indivíduos.

Figura 7. Indivíduos regenerantes de angico (Anadenanthera colubrina) sobreviventes em população natural em parcelas plotadas em área de mata no período de dezembro de 2014 a julho de 2015, Bananeiras, Paraíba

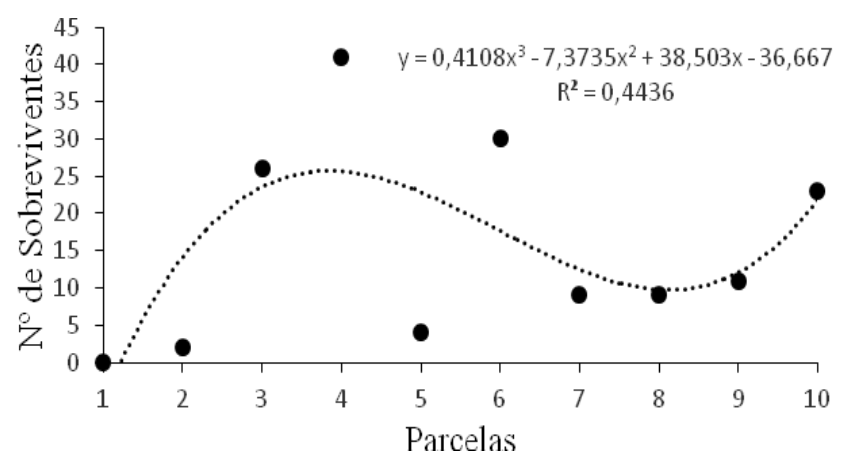

Observou-se no fragmento estudado, que a dinâmica de regeneração da espécie nas parcelas, foram influenciadas por vários fatores, e havendo grande mortalidade de plântulas, o relevo também pode ter interferido na regeneração, porém, muitos indivíduos foram recrutados nestas parcelas, havendo a presença de regenerantes, entretanto muitos não conseguiram se estabelecer. Com menor competição e maior disponibilidade hídrica, na parcela 4, observou-se crescimento no número de indivíduos ao final do experimento, onde na primeira leitura, realizada em dezembro de 2014, identificamos 23 indivíduos, e ao final, no mês de julho de 2015 tínhamos 41 indivíduos, um crescimento de 78,26\% do total de indivíduos regenerantes. Identificamos também aumento no número de indivíduos na parcela 9 , esta parcela não apresentou interferência antrópica e tem baixa competição com espécies herbáceas.

Assim, a perpetuação dessa espécie no fragmento estudado depende, principalmente, de condições apropriadas para germinação de sementes logo que dispersas e da presença das plantas jovens que ocorrem no sub-bosque da floresta.

Com relação ao índice de mortalidade (Figura 8), observou-se que variou conforme a distribuição das parcelas, isso pode ter ocorrido por estarem alocadas em locais com maior ação antrópica, e competição de outras espécies já que se localizam próximo a borda do fragmento florestal, e também de uma trilha de pedestres. Em outras parcelas, observou-se a menor taxa de mortalidade, chegando a $53,33 \%$, que pode ser explicada, pelo fator de menor influência antrópica e por mais disponibilidade de luz, e por ser uma espécie halófita, se desenvolve melhor na presença de luminosidade e menor competição com outras espécies.
Figura 8. Taxa de mortalidade de indivíduos de angico (Anadenanthera colubrina) em população natural de parcelas plotadas em área de mata no período de dezembro de 2014 a julho de 2015, Bananeiras, Paraíba

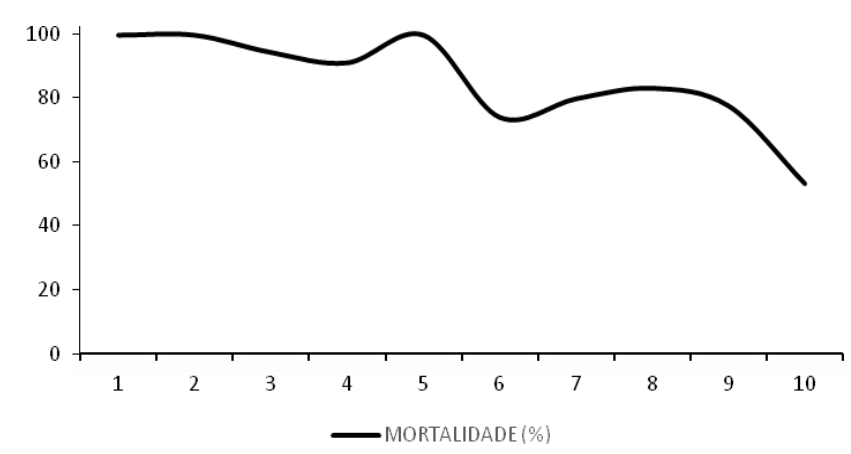

A avaliação do potencial regenerante necessita da compreensão dos processos associados à manutenção de certos grupos funcionais, é de importância ímpar para se definirem estratégias ligadas à conservação desses ambientes e a previsão de cenários de mudanças estruturais, associados a variáveis em diferentes escalas (LEYSER et al., 2012).

A maioria das populações de espécies tropicais tem a mortalidade concentrada nas classes menores (SOLBRIG, 1981) e as causas são a presença de patógenos ou herbívoros e a competição entre plântulas ou entre plântulas e indivíduos adultos (AUGSPURGER, 1983; SWAINE et al., 1987; HOWE, 1990). Com isso, diversos fatores bióticos e abióticos implicam nos resultados obtidos na pesquisa, no qual, os regenerantes de angico Anandenanthera colubrina estão expostos durante o período de plântula no fragmento estudado.

No fragmento as ações antrópicas, ou mesmo, bióticas como queda de árvores e chuvas nas parcelas com o táxon, ou mesmo, o relevo do local pode ter interferido no desenvolvimento das plântulas. As parcelas que obtiveram $100 \%$ de mortalidade estão localizadas próximo a trilhas existentes no fragmento florestal, se tornando mais susceptíveis a ação do ser humano, em outras parcelas constatou-se a presença da competição com espécies herbáceas.

A competição entre os regenerantes tende a beneficiar a diversidade, ocorrendo maior mortalidade em espécies muito abundantes, de modo que a proporção entre as espécies se torna mais homogênea nas classes de maior tamanho (SUGANUMA et al., 2013). Em estudo semelhante com plântulas da mesma espécie com altura de até $1 \mathrm{~m}$ de altura, Medeiros et al. (2016) encontrou um índice de sobreviventes entre os meses estudados com redução a cada mês, onde, apenas $31,7 \%$ havia sobrevivido, ou seja, quase $70 \%$ dos regenerantes morreram em apenas 10 meses de estudo. Neste trabalho, encontramos uma taxa de mortalidade de $85,45 \%$ em indivíduos regenerantes com tamanho de até $0,30 \mathrm{~m}$ de altura, a taxa de mortalidade encontrada no estudo do banco de plântulas, foi alta, porém, os indivíduos sobreviventes, provavelmente se estabelecem no dossel. A localização geográfica das parcelas atrelada aos diversos fatores, podem ter influenciado na obtenção dos dados referentes a regeneração de Anadenanthera colubrina. 


\section{CONCLUSÕES}

O táxon A. colubrina apresentou uma mortalidade alta de $85,45 \%$ do total das parcelas estudadas na fase de plântula.

$\mathrm{Na}$ população de regenerantes no fragmento estudado diversos fatores bióticos e abióticos interferem no desenvolvimento, além da ação antrópica que apresenta alta interferência no desenvolvimento das plântulas.

$\mathrm{O}$ crescimento de plântulas de $A$. colubrina foi maior onde as parcelas estão localizadas ao centro do fragmento estudado, ou seja, em área com menor influência antrópica, ou próximo a fontes hídricas.

A perpetuação dessa espécie no fragmento estudado depende, principalmente, de condições apropriadas para germinação de sementes logo que dispersas e da presença das plantas jovens que ocorrem no subbosque da floresta.

\section{AGRADECIMENTOS}

Ao Centro de Ciências Humanas, Sociais e Agrárias de Bananeiras, PB, a PRPG/UFPB e o CNPq, pela concessão da bolsa e fomento da pesquisa

\section{REFERÊNCIAS}

ALVES, L. F.; METZGER, J. P. A regeneração florestal em áreas de floresta secundária na Reserva Florestal do Morro. Biota Neotrop. v.6, p.1-26, 2006. http://dx.doi.org/10.1590/S1676-06032006000200005.

AVILA, A. L. D.; ARAUJO, M. M.; LONGHI, S. J.; SCHNEIDER, P. R.; CARVALHO, J. O. P. D. Estrutura populacional e regeneração de espécies arbóreas na Floresta Nacional de São Francisco de Paula, Rio Grande do Sul. Ciência Florestal, v.26, n.3, p.825-838. 2016 http://dx.doi.org/10.5902/1980509824211.

ANDRADE, L. A.; FABRICANTE, J. R.; ALVES, A. S. Algaroba (Prosopis juliflora (Sw.) DC.): Impactos sobre a fitodiversidade e estratégias de colonização em área invadida na Paraíba, Brasil. Natureza e Conservação, v.6, n.2, p.61-67, 2008.

AUGSPURGER, C. K. Seed dispersal of tropical tree Platypodium elegans, and the escape of its seedlings from fungal pathogens. Journal of Ecology v.71, p.759-771, 1983. http://dx.doi.org/10.2307/2259591.

BARBOSA, M. R. V.; AGRA, M. F.; SAMPAIO, E. V. S. B.; CUNHA, J. P.; ANDRADE, L. A. Diversidade florística na Mata do Pau-Ferro, Areia, Paraíba. In: PÔRTO, K.C.; CABRAL, J. J. P.; TABARELLI, M. (Orgs). Brejos de altitude em Pernambuco e Paraíba, História Natural, Ecologia e Conservação. Brasília. Ministério do Meio Ambiente, p.111-122, 2004.

BARRETTO, S. S. B.; FERREIRA, R. A. Aspectos morfológicos de frutos, sementes, plântulas e mudas de leguminosae mimosoideae: Anadenanthera colubrina (vellozo) brenan e Enterolobium contortisiliquum (vellozo) morong. Rev. bras. Sementes. v.33, n.2, p.223-232. 2011, http://dx.doi.org/10.1590/S0101-31222011000200004.
BURSLEM, D. F. R.; GRUBB, P. J.; TURNER, I. M. Responses to simulat ed drought and elevated nutrient supply among shade-tolerant tree seedlings of lowland tropical forest in Singapore. BIOTROPICA v.28, n.4, p.636-648, 1996. http://dx.doi.org/10.2307/2389050.

DANIEL, O.; JANKAUSKIS, J. Avaliação de metodologia para o estudo do estoque de sementes do solo. SÉRIE IPEF, Piracicaba, v. 41-42, p.18-26, 1989.

EMBRAPA. Centro Nacional de Pesquisa de Solos (Rio de janeiro, RJ). Sistema brasileiro de classificação dos solos. Brasília: Embrapa-SPI, 1999. 412p.

HARMS, K. E., WRIGHT, S. J., CALDERÓN, O., HERNÁNDEZ, A.; HERRE, E. A. Pervasive densitydependent recruitment enhances seedling diversity in a tropical forest. Nature. 404:493-495, 2000. http://dx.doi.org/10.1038/35006630

LEYSER, G.; ZANIN, E. M.; BUDKE, J. C.; MÉLO, M. A.; HENKE-OLIVEIRA, C. Regeneração de espécies arbóreas e relações com o componente adulto em uma floresta estacional no vale do rio Uruguai, Brasil. Acta Botanica Brasilica, v. 26, n. 1, p. 74-83, 2012. http://dx.doi.org/10.1590/S010233062012000100009

LORENZI, H. Árvores brasileiras: manual de identificação e cultivo de plantas arbóreas do Brasil. 4.ed Nova Odessa: Instituto Plantarum, 2002. p. 188.

MARCHESINI, V. A.; SALA, O. E.; AUSTIN, A. T. Ecological consequences of a massive fl owering event of bamboo (Chusquea culeou) in a temperate forest of Patagonia, Argentina. Journal of Vegetation Science. V.40, n.3, p.424-432. 2009. http://dx.doi.org/10.1111/j.16541103.2009.05768

MARENCO, R. A.; ANTEZANA-VERA, S. A.; GOUVÊA, P. R. S.; CAMARGO, M. A. B.; OLIVEIRA, M. F. de; SANTOS, J. K. S. Fisiologia de espécies florestais da Amazônia: fotossíntese, respiração e relações hídricas. Rev. Ceres. v.61, p.786-799, 2014. http://dx.doi.org/10.1590/0034$737 \times 201461000004$.

MEDEIROS, R. L. S. de; SOUZA, V. C. de; BARBOSA NETO, M. A.; ARAÚJO, L. de; BARBOSA, A. S.; MEDEIROS, R. L. S. de; Estrutura da regeneração natural de Anadenanthera colubrina em fragmento de brejo de altitude em Bananeiras, PB. Pesq. Flor. Bras. v. 36, n. 86, p.95-101, 2016. https://doi.org/10.4336/2016.pfb.36.86.887

MEDEIROS, R. L. S.; SILVA, J. J. R. S.; SOUZA, V. C.; NASCIMENTO, R. G. S.; ANJOS, F. Fenologia de Anadenanthera colubrina (Vell.) Brenan em fragmento de Floresta Ombrófila Aberta na Paraíba. Agropecuária Científica no Semiárido. v.13, n.1. p.35-40. 2017.

MULLER-DOMBOIS, D.; ELLEMBERG, H. Aims and methods of vegetation ecology. New York: John Wiley \& Sons, $1974,547 \mathrm{p}$. 
PALUDO, G. F.; MANTOVANI, A. REIS, M. S. dos; Regeneração de uma população natural de Araucaria angustifolia (Araucariaceae). Rev. Árvore. v.35, n.5, p. 11071119, 2011. http://dx.doi.org/10.1590/S010067622011000600017.

ORELLANA, E.; FIGUEIREDO FILHO, A.; PÉLLICO NETTO, S.; NOGUEIRA DIAS, A. Alteração na estrutura diamétrica de uma Floresta Ombrófila Mista no período entre 1979 e 2000. Revista árvore, v. 30, n. 2, p. 283-295, 2006. http://dx.doi.org/10.1590/S0100-67622006000200016.

REIS, A.; TRES, D. R.; SCARIOT, E. C. Restauração na floresta ombrófila mista através da sucessão natural. Pesquisa Florestal Brasileira, v. 55, p. 67-73. 2007.

SOLBRIG, O. T. Studies on the population biology of the genus Viola. II. The effect of plant size on fitness in Viola sororia. Evolution v.35, p.1080-1093, 1981. http://dx.doi.org/ 10.1111/j.1558-5646.1981.tb04977.

SUGANUMA, M. S.; ASSIS, G. B. de; MELO, A. C. G. de; DURIGAN, G. Ecossistemas de referência para restauração de matas ciliares: existem padrões de biodiversidade, estrutura florestal e atributos funcionais?. Rev. Árvore. v.37, n.5, p.835-847. 2013. http://dx.doi.org/10.1590/S010067622013000500006 .

SWAINE, M. D., LIEBERMAN, D.; PUTZ, F.E. The dynamics of tree population in tropical forest: a review. Journal of Tropical Ecology 3:359-366, 1987.

WEINER, J. Size hierarchies in experimental populations of annual plants. Ecology 66:743-752, 1985. http://dx.doi.org/10.2307/1940535. 